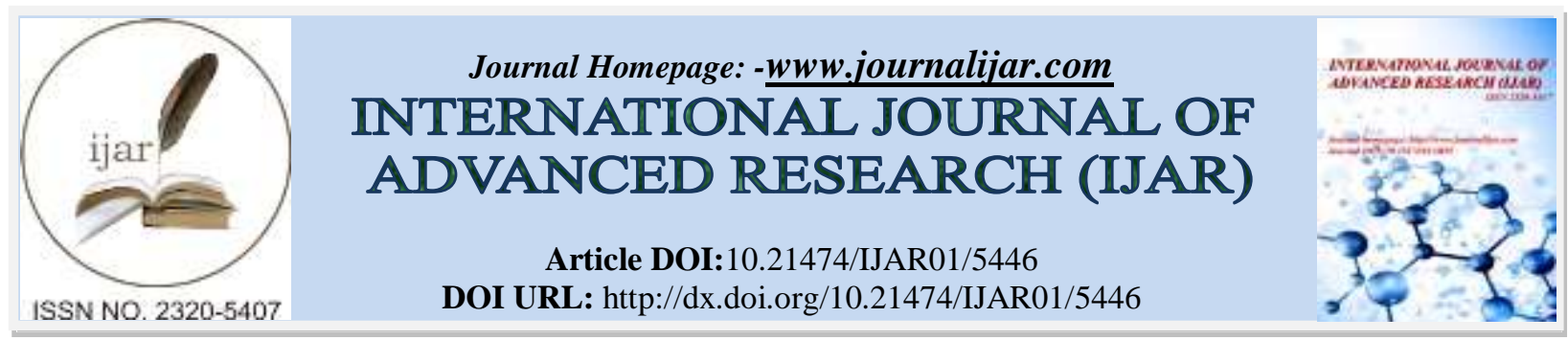

RESEARCH ARTICLE

\title{
MICROSATELLIT MARKERS BAT25 AND BAT26 IN SUBJECTS WITH COLORECTAL CANCER IN SENEGAL.
}

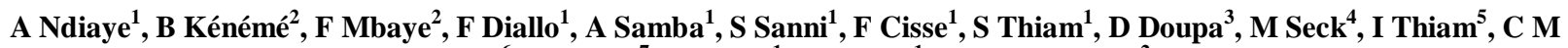

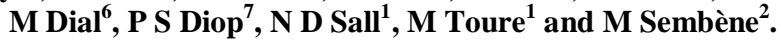 \\ 1. Laboratory of Molecular Biochemistry-Biology Cheikh Anta Diop University of Dakar, (Senegal). \\ 2. Department of Animal Biology, Faculty of Science and Technology, Cheikh Anta Diop University, Dakar (Senegal). \\ 3. Laboratory of Molecular Biochemistry-Biology Training and Research Unit (UFR), Faculty of Health Sciences, Gaston \\ Berger University, Saint Louis (Senegal). \\ 4. Department of general surgery, Aristide Le Dantec Hospital Dakar (Senegal). \\ 5. Laboratory of anatomopathology, Aristide Le Dantec Hospital Dakar (Senegal). \\ 6. Laboratory of anatomopathology, Grand Yoff Hospital, Dakar (Senegal). \\ 7. Department of digestive surgery and hepatobiliary-Cancerology, Grand Yoff Hospital, Dakar (Senegal).
}

\section{Manuscript Info}

Manuscript History

Received: $x x x x x x x x x x x x x x x$ Final Accepted: $x \times x x x x x x x x x$ Published: $\mathrm{xxxxxxxxxxxxxxx}$

Key words:-

CRC, Mutations,BAT25, BAT26.

\section{Abstract}

Introduction: Colorectal cancer (CRC) is becoming more and more frequent. Diagnosis is essentially based on the identification of mutations at the level of markers selected at the international meeting held in Bethesda (December 1997). We distinguish BAT25 and BAT26 among these markers. Because of their polymorphism, they have been incriminated in several cancer pathologies such as CRC.

Objective: The objective of this study is to evaluate the level of polymorphism of the identified two markers in a Senegalese population with CRC.

Methodology: The study involved 29 patients with CRC. They were selected at different health care facilities, namely Principal Hospital, Grand Yoff Hospital and the Aristide Le Dantec Teaching Hospital in Dakar. A sample of healthy tissue and another of tumor tissue were extracted from each patient. To serve as controls, other samples were taken from subjects without CRC. The samples were sent to the laboratory for DNA extraction. The BAT25 and BAT26 markers were then amplified by PCR and sequenced. In each person, the sequenced BAT25 and BAT26 loci were contiguous to have a single sequence. Dnasp version 5.10, MEGA version 6.06 and the Harlequin version 3.5.1.3 program were used to highlight the parameters of variability, genetic distances and genetic structuring test according to the clinical parameters of patients such as age, sex and the location of the tumor.

Results: The comparison between healthy tissue and tumor tissue from each patient revealed a high variability of BAT25 and BAT26 loci with mutations specific to the tumor tissues. This difference is confirmed by the nature of the mutations observed. Of these mutations, the most frequent is the deletion of a thymine at position 72 (72delT). This variability between healthy tissue and tumor tissue is further confirmed by the genetic distance of Nei. On the other hand, no genetic 
structuration of the BAT25 and BAT26 loci was observed as a function of clinical-pathological parameters.

Face biometrics assumes an essential part in different authentication applications. Yet, there is a design issues exists to ensure the genuine person along with its originality being alived. For the improvement of such kind of robust framework of face verification along with anitspoofing, the database should include three kinds of data i.e. Genuine, Fake and Imposter. In this paper, a database is designed to work for face verification and anti-spoofing technique. The Local Binary Pattern is adopted to extract the features and calculate the scores for genuine, fake and imposter attacks. This research would provide a more realistic and challenging platform for facial anti-spoofing and verification research.

Copy Right, IJAR, 2017,. All rights reserved.

\section{Introduction:-}

Colorectal cancer has become a real public health problem. In Africa, it represents 1 to $3 \%$ of cancer cases (Padonou et al., 2013). It occurs at a younger age, 46 years on average. The fact that cancer diagnosis is generally performed at a later stage may justify the mutilating interventions and the fear of cancer prognosis (Padonou et al., 2000). In Senegal, despite the absence of a cancer registry and the virtual absence of studies on colorectal cancers, prevalence is beginning to reach worrying proportions. Investigations have shown different types of colorectal cancers, two of which are exclusive. On the one hand, we have the Chromosomal instability (CIN) type, characterized by chromosomal instability, accompanied by numerous losses of heterozygosity and the hyperploid, and diploid type MSI or MIN (Microsatellite Instability) on the other hand, which has more restricted alterations at the nucleotide level (Hamelin et al., 2005). Due to contradictory results relating to the frequency of the MSI type in various human tumors, an international consensus meeting was necessary to reflect on the issue. The latter took place in Bethesda in December 1997, and the report was published a year later (Boland et al., 1998). A panel of 5 microsatellites, including BAT-25 and BAT-26, as well as 3 dinucleotide markers (D5S346, D2S123 and D17S250) was proposed at this meeting. Regarding MSI diagnosis, the 3 markers were added to the panel because BAT25 and BAT26 may have some polymorphism depending on the group studied (Boland et al., 1998). Within that framework, we conducted this study to evaluate the polymorphism of BAT25 and BAT26 loci in CRC cases in Senegal. More specifically this study will allow us:-

assess the variability and genetic diversity of BAT25 and BAT6;

identify specific mutations by comparing healthy and tumor tissues in each patient;

determine whether there is a genetic differentiation of CRCs, based on some clinic-pathological characteristics (age, sex, location)

\section{Methodology:- \\ Patients:-}

This is a prospective study on 29 patients with colorectal cancer. Patients were recruited at the anatomopathological laboratories of health care facilities such as the Principal Hospital, Grand Yoff Hospital and the Aristide Le Dantec Teaching Hospital in Dakar.

In each patient, a healthy tissue sample and a tumor tissue sample were extracted and then stored in $96 \%$ alcohol for genetic analysis.

Non-CRC individuals were also sampled to serve as controls. Each group was put into a population.

Subjects were aged between 35 and 92 years and were divided according to their age (30-60 years, and above 60 years) sex (male, female) and tumor localization (colon, rectum) (Table I)

Table 1:- Clinical and anatomopathological characteristics of the population

\begin{tabular}{|l|l|l|}
\hline Variables & Quantity & Percentage (\%) \\
\hline Sex & & \\
\hline
\end{tabular}




\begin{tabular}{|l|l|l|}
\hline Male & 16 & 55,2 \\
\hline Female & 13 & 44,8 \\
\hline Age (years) & & \\
\hline$<30$ & 0 & 0 \\
\hline $30-60$ & 14 & 48,3 \\
\hline$>60$ & 15 & 51,7 \\
\hline Localization & & \\
\hline Colon & 22 & 75,9 \\
\hline Rectum & 7 & 24,1 \\
\hline
\end{tabular}

DNA Extraction, Amplification and Sequencing:-

All DNA tissues were extracted using the QIAGEN kit (QI Amp DNA FFPE Tissue) and the Promega kit. DNA quality was checked by electrophoretic migration on 1.5\% agarose gel. For each marker (BAT25 and BAT26), the amplification was performed in a reaction volume of $50 \mu \mathrm{l}$. The PCR was performed with $34.9 \mu 1$ of Mali water, $5 \mu 1$ of 10X tampons, $1 \mu \mathrm{l}$ of $\mathrm{MgCl}$ 2, $2 \mu \mathrm{l}$ of dNTP, $2.5 \mu \mathrm{l}$ of each primer, $0.1 \mu \mathrm{l}$ of Taq and $2 \mu \mathrm{l}$ of concentrated DNA. The used primers were described by Buhard et al. (2006). The amplified products were sequenced with a 3730xl ABI sequencer. Table II highlights the primers used and shows the conditions of amplification.

Table 2:- Oligonucleotide sequences and amplification conditions

\begin{tabular}{|c|c|c|c|c|c|c|}
\hline $\begin{array}{l}\text { Studie } \\
\mathrm{d} \\
\text { Marke } \\
\text { rs }\end{array}$ & $\begin{array}{l}\mathrm{N}^{\circ} \\
\text { Genbank }\end{array}$ & $\begin{array}{l}\text { Repea } \\
\text { d caus }\end{array}$ & $\begin{array}{l}\text { ate } \\
\text { se }\end{array}$ & Primer Sense & Anti-sense primer & $\begin{array}{l}\text { Conditions } \\
\text { of } \\
\text { amplificati } \\
\text { on }\end{array}$ \\
\hline $\begin{array}{l}B A T- \\
25\end{array}$ & X69313 & $\begin{array}{l}(\mathrm{T}) \\
25\end{array}$ & $\begin{array}{l}120- \\
124 \mathrm{pb}\end{array}$ & $\begin{array}{l}\text { TCGCCTCCAAGAATGTAA } \\
\text { GT }\end{array}$ & $\begin{array}{l}\text { TCTGCATTTTAACTATGG } \\
\text { CTC }\end{array}$ & $\begin{array}{lr}94^{\circ} & 10 \mathrm{mn} \\
30 & \text { cycles } \\
\left(94^{\circ}\right. & 45 \mathrm{~s}, \\
58^{\circ} & 45 \mathrm{~s}, \\
72^{\circ} & 45 \mathrm{~s}) \\
72^{\circ} & 10 \mathrm{mn}\end{array}$ \\
\hline $\begin{array}{l}B A T- \\
26\end{array}$ & $\begin{array}{l}\text { AY6018 } \\
51\end{array}$ & (A) 26 & $\begin{array}{l}116- \\
120 \mathrm{pb}\end{array}$ & $\begin{array}{l}\text { TGACTACTTTTGACTTC } \\
\text { AGCC }\end{array}$ & $\begin{array}{l}\text { AACCATTCAACATTTTTA } \\
\text { ACCC }\end{array}$ & $\begin{array}{lr}95^{\circ} & 5 \mathrm{mn} \\
35 & \text { cycles } \\
\left(95^{\circ}\right. & 30 \mathrm{~s}, \\
47^{\circ} & 1 \mathrm{mn}, \\
70^{\circ} & 1 \mathrm{mn}) \\
70^{\circ} & 10 \mathrm{mn} \\
\end{array}$ \\
\hline
\end{tabular}

Genetic analysis:-

Polymorphism analysis and genetic diversity of BAT25 and BAT26:-

After correction, cleaning and alignment of sequences obtained for each marker, polymorphism parameters such as the length of the sequences, the number of variable sites (polymorphs), the number of informative sites in parsimony, the number of mutations, Haplotypes and standard parameters of genetic diversity such as haplotype diversity (he) and nucleotide diversity (Pi) were determined using the Dnasp version 5.10 software (Librado and Rozas, 2009) in each of the 3 populations (controls, healthy tissues, Tumor tissues). The average number of nucleotide differences (k) was reported under Dnasp version 5.10.01 (Librado and Rozas, 2009). Nucleotide frequencies and the nature of the mutations were determined using the MEGA 6.06 software (Tamura et al., 2013).

Both genes were contiguous to obtain unique sequences. The mutations were compared at the intra-individual level (between healthy tissue and tumor tissue) to characterize specific mutations.

\section{Genetic Differentiation Tests:-}

The intra - and inter - individual Nei gene distances of contiguous sequences were calculated under MEGA 6.06 (Tamura et al., 2013) using the two - parameter Kimura model. 
To detect the presence of tumor tissues, a genetic differentiation based on clinical and pathological parameters, we carried out the genetic differentiation test (Fst) with Arlequin program 3. 5. 1. 3 (Excoffier et al., 2010). In this specific case, groups were related to the clinical and pathological parameters (sex, age, location).

\section{Results:-}

Unlike tumor tissues, BAT25 controls and healthy tissues showed no variability. Whereas for BAT26, mutations were found in both healthy and tumor tissues (Table III). This difference is reflected in the number of haplotypes with seven (7) haplotypes found for BAT25 (1 haplotype grouping controls and healthy tissues, and 6 haplotypes for tumor tissues), twenty-six (26) haplotypes for BAT26 Haplotype for controls, 3 haplotypes for healthy tissues and 22 for tumor tissues) [Table III]. Regarding tumor tissues, For BAT25 all the mutations found were trans versions, whereas for BAT26, $28.91 \%$ of the mutations found were transitions and $71.09 \%$ of the transversions. The parameters of the healthy inter-tissue and tumor tissue of the two markers were different (Table 3).

Table 3:- Index of genetic variability of sequences

\begin{tabular}{|c|c|c|c|c|c|c|}
\hline \multicolumn{4}{|c|}{ BAT25 } & \multicolumn{3}{|c|}{ BAT26 } \\
\hline Settings & Witnesses & TS & TT & Witnesses & TS & TT \\
\hline Sample size & 10 & 7 & 22 & 5 & 7 & 29 \\
\hline Number of sites & 222 & 222 & 222 & 108 & 108 & 108 \\
\hline Monomorphic sites & 222 & 222 & 218 & 108 & 105 & 94 \\
\hline Polymorphic sites & 0 & 0 & 4 & 0 & 3 & 8 \\
\hline Haplotypes & 1 & 1 & 6 & 1 & 3 & 22 \\
\hline Transitions (\%) & 33,33 & 33,33 & 0 & 33,33 & 23,16 & 28,91 \\
\hline Transversions (\%) & 66,66 & 66,66 & 100 & 66,66 & 76,84 & 71,09 \\
\hline Mutation rate $(\mathrm{R})$ & 0,41 & 0,41 & 0 & 0,46 & 0,33 & 0,42 \\
\hline $\mathrm{Hd}$ & 0 & 0 & 0,6407 & 0 & 0,66 & 0,97 \\
\hline $\mathrm{Pi}$ & 0 & 0 & 0,0015 & 0 & 0,0105 & 0,025 \\
\hline $\mathrm{K}$ & 0 & 0 & 0,338 & 0 & 1,14 & 2,59 \\
\hline \multicolumn{6}{|c|}{ Nucleotide discrepancy rate between healthy and tumor inter-tissues } & \\
\hline & \multicolumn{3}{|l|}{ BAT25 } & \multicolumn{2}{|l|}{ BAT26 } & \\
\hline $\mathrm{Pi}$ & \multirow{2}{*}{\multicolumn{2}{|c|}{$\begin{array}{l}0,00119 \\
0,26\end{array}$}} & & \multicolumn{2}{|l|}{0,024} & \\
\hline $\mathrm{K}$ & & & 0,26 & \multicolumn{2}{|l|}{2,53} & \\
\hline
\end{tabular}

The intra-individual analysis of contiguous sequences reveals a variable expressivity of BAT25 and BAT26 loci between healthy and tumor tissues, with specific mutations to the tumor tissue for each patient. For patient 1 , we found the deletion-type ( 72 delT) and substitution of adenine (replaced with C and G) and guanine (replaced by A and T) mutations in the tumor tissue compared to healthy tissue. With patients $2,3,4,5$ and 7 , in addition to other substitutions (71delT, 239 G, A, 304delA, 305delA, 324T, G, 70T, G, 71T, G, 32T, A, 265A, C) the same mutations were found but at different positions for some substitutions ( $238 \mathrm{~A}, \mathrm{C})$. The mutations found in the tumor tissue of patient 6 were only deletions (72 delT, 240 delG).

Table 4:- Mutations in healthy tissues and tumor tissues of contiguous sequences

\begin{tabular}{|c|c|c|c|c|c|c|c|}
\hline Patients & 1 & 2 & 3 & 4 & 5 & 6 & 7 \\
\hline Mutations & $\begin{array}{ll}\text { TS } & \text { TT }\end{array}$ & $\begin{array}{ll}\text { TS } & \text { TT }\end{array}$ & $\begin{array}{|ll|}\text { TS } & \text { TT }\end{array}$ & $\begin{array}{ll}\text { TS } & \text { TT }\end{array}$ & $\begin{array}{ll}\text { TS } & \text { TT }\end{array}$ & $\begin{array}{ll}\text { TS } & \text { TT }\end{array}$ & $\begin{array}{ll}\text { TS } & \text { TT }\end{array}$ \\
\hline $71 \mathrm{~T}, \mathrm{G}$ & T $\quad \mathrm{G}$ & & & & & & \\
\hline 72 delT & T del & T del & $\begin{array}{ll}\mathbf{T} & \text { del }\end{array}$ & del & T del & $\begin{array}{ll}\text { T } & \text { del }\end{array}$ & del \\
\hline $239 \mathrm{~A}, \mathrm{C}$ & $\begin{array}{ll}\text { A } & \text { C }\end{array}$ & & & & & & \\
\hline $265 \mathrm{~A}, \mathrm{C}$ & A $\quad$ C & & & & & & A \\
\hline $273 \mathrm{G}, \mathrm{A}$ & $\begin{array}{ll}\mathrm{G} & \mathrm{A} \\
\end{array}$ & & & & & & \\
\hline $291 \mathrm{~A}, \mathrm{G}$ & A $\quad G$ & & & & & & \\
\hline 319 A, G & A $\quad$ G & & & & & & \\
\hline $324 \mathrm{G}, \mathrm{T}$ & G $\quad \mathrm{T}$ & & & & & & \\
\hline 71 delT & & $\mathrm{T} \quad \mathrm{del}$ & & $\begin{array}{ll}\mathrm{T} & \text { del }\end{array}$ & & & \\
\hline $238 \mathrm{~A}, \mathrm{C}$ & & A $\quad$ C & $\mathbf{C}$ & $\mathbf{A}$ & C & & $\mathbf{A}$ \\
\hline
\end{tabular}




\begin{tabular}{|c|c|c|c|c|c|c|c|c|c|c|c|}
\hline $239 \mathrm{G}, \mathrm{A}$ & & $\mathbf{A}$ & G & A & G & $\mathbf{A}$ & G & A & & G & A \\
\hline 304 delA & A & del & & & & & & & & & \\
\hline 305 delA & & & A & del & A & del & & & & & \\
\hline $324 \mathrm{~T}, \mathrm{G}$ & & & & & $\mathrm{T}$ & G & & & & & \\
\hline $70 \mathrm{~T}, \mathrm{G}$ & & & & & & & $\mathrm{T}$ & $\mathrm{G}$ & & & \\
\hline $71 \mathrm{~T}, \mathrm{G}$ & & & & & & & $\mathrm{T}$ & $\bar{G}$ & & $\mathrm{~T}$ & $\mathrm{G}$ \\
\hline 240 delG & & & & & & & & & G $\quad$ del & & \\
\hline $32 \mathrm{~T}, \mathrm{~A}$ & & & & & & & & & & $\mathrm{~T}$ & A \\
\hline
\end{tabular}

$\mathrm{TS}=$ healthy tissue $; \mathrm{TT}=$ tumor tissue $;$ Del $=$ deletion

Determining the intra-individual genetic distance of contiguous sequences confirms the variable expressivity of the BAT25 and BAT26 loci between healthy tissue and tumor tissue for the same individual (Table 5).

Table 5:- Genetic distances between healthy tissue and intra-individual tumor tissue

\begin{tabular}{|l|l|l|l|}
\hline Patients & Genetic Distance & Standard Deviation \\
\hline 1 & & 0,016 & 0,007 \\
\hline 2 & 0,006 & 0,004 \\
\hline 3 & 0,006 & 0,004 \\
\hline 4 & 0,009 & 0,005 \\
\hline 5 & 0,009 & 0,004 \\
\hline 6 & 0 & 0 \\
\hline 7 & 0,012 & 0,006 \\
\hline
\end{tabular}

The analysis of the molecular variance relating to the defined groups according to the clinical-pathological parameters showed that there was no genetic structuring based neither on sex, age nor on the localization (P-value not statistically significant) [Table 6].

Table 6:- Genetic structure based on clinical parameters

\begin{tabular}{|c|c|c|c|}
\hline 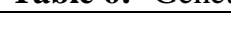 & \multicolumn{3}{|c|}{ Sex } \\
\hline Amplified gene & Variation source & $\%$ of variation & FST (P-value) \\
\hline \multirow{10}{*}{ BAT25/BAT26 } & Intra groups & 100,98 & \\
\hline & Inter groups & $\begin{array}{l}-0,98 \\
\end{array}$ & $0,0098(0,49)$ \\
\hline & \multicolumn{3}{|c|}{ Age } \\
\hline & variation source & $\%$ of variation & FST (P-value) \\
\hline & Intra groups & 100,51 & \\
\hline & Inter groups & $-0,51$ & $0,0051(0,54)$ \\
\hline & \multicolumn{3}{|c|}{ Localization } \\
\hline & variation source & $\%$ of variation & FST (P-value) \\
\hline & Intra groups & 96,52 & \\
\hline & Inter groups & 3,48 & $0,034(0,26)$ \\
\hline
\end{tabular}

\section{Discussion:-}

In this study, we tried to determine the polymorphism of the BAT25 and BAT26 loci which are part of the selected markers of the National Cancer Institute (Hamlin, 2005) and which plays a role in the diagnosis of CRC. Within that framework, we studied the genetic variability. Then the two markers were associated to obtain contiguous sequences. For these sequences, we determined the types of mutation obtained by comparing healthy and tumor tissues from each patient. Genetic structuring according to clinical parameters (age, sex, localization) was evaluated for all tumor tissues. 
By comparing mutations in healthy and tumor tissues of the same individual, we found that some mutations were specific to tumor tissues. Most of these mutations were substitutions of A by $\mathrm{C}$ in the tumor tissue, except for patient 1 where the adenines are replaced by guanine in positions 291 and 319. These substitutions could be involved in the occurrence of CRC in the Senegalese population. A series of studies carried out by Pyatt et al (1999), on tumor tissues, showed that a reduction in the number of repeated adenine is often found in CRCs. In the study on breast cancer conducted by Mbaye et al (2015), results showed a loss of a variable number of mononucleotides on the two loci. Literature review shows that numerous studies have demonstrated the polymorphism of the BAT25 and BAT26 loci, which vary according to the study population. Zheng et al (2011) showed that the BAT25 locus highlights some variability in a Chinese population. A study by Zhou et al (1997) showed a reduction in the number of the $B A T 26$ locus adenine in cancerous tissues.

Other studies with a much wider sampling could make us believe that the observed mutations have a causal role in the disease.

The deletion of thymine at position 72 in tumor tissues is observed in all patients. This result reinforces the hypothesis that a reduction in the number of repetitions of thymine is frequent in most colorectal tumors (Pyatt et al., 1999). Mutations 238A, C and 239C, A are noted in 5 of the 7 patients. In addition to the deletion, these substitutions could be involved in the disease.

Besides these three mutations types, other mutations are transient and are observed only in one patient except $265 \mathrm{~A}$, C; 71delT; 305; 71T, G (observed in 2 patients). This variable expressivity observed from one patient to another shows the heterogeneity of the mutations in tumors. This heterogeneity has been demonstrated by some authors.

According to Billaud (2012), the exchanges that exist between cancer cells and their environment are not uniform and can cause mutations that vary according to the regions of the tumor. When it comes to Swanton, et al. (2012), they showed that the tumor is not an isotropic mass and that there is a continuous process of mutations and selections giving rise to genetically distinct populations, each having its own topographic distribution.

Intra-individual genetic distances further confirm that there is a difference between healthy tissue and tumor tissue of the same individual. For patient 7, the difference is much greater compared to the others with a value $d=0.012$.

The number of ganglions found in the meso-colon is variable from one patient to another, but all these ganglions are free except for patient 7 in whom the histological examination revealed a tumor ganglion among the four. Each patient has at least 4 mutations except for patient $6(\mathrm{~d}=0)$, who has only 2 mutations that are deletions (Mega software does not include deletions to calculate distances). This result confirms that there is a molecular difference between healthy and tumor tissues in the same individual. This indicates that there is a polymorphism of BAT25 and BAT26 loci in CRC cases in Senegal and that this polymorphism could play a role in the occurrence of this pathology but also in tumor progression. Nevertheless, no genetic structuring according to clinical-pathological parameters was noted for BAT25 and BAT26 loci. This lack of association was highlighted in the study of Mbaye, which focused on breast cancer in Senegalese women.

\section{Conclusion:-}

Our study showed that there is variability of BAT25 and BAT26 loci between a healthy and a tumor tissues with different mutations from one patient to another. This variable is confirmed by intra-individual genetic distances. This variable expressiveness of the BAT25 and BAT26 loci confirms their role in the colorectal cancers.

\section{References:-}

1. Padonou N., Bagman k. B., Kodjoh N., Agbo N., 2000. Les cancers colorectaux à la clinique universitaire de chirurgie viscérale du chu de Cotonou : à propos de 10 cas observés en 7 ans. Médecine d'Afrique noire

2. Hamelin R., 2005. Instabilité des microsatellites et cancers du côlon, Hépato-Gastro, vol.12, numéro1

3. Boland C.R., Thibodeau S.N., Hamilton S.R., Sidransky D., Eshleman J.R., Burt RWA. 1998. National Cancer Institute workshop on microsatellite instability for cancer detection and familial predisposition : development of international criteria for the determination of microsatellite instability in colorectal cancer. Cancer Res; 58 : $5248-57$.

4. Buhard O., Cattaneo F., Wong Y. F., Yim S.F., FredmanE., Flejou J.F.O., Duval A., +Hamelin R., 2006. Multipopulation analysis of polymorphism repeats used to determine the microsattelite instability status of human tumor. Journal of clinical Oncology 24(4): 241-251 
5. Librado P., Rozas J., 2009. DnaSP version 5: a software for comprehensive analysis of DNA polymorphism data, Bioinfor.; 25: 1451-1452

6. Tamura K., Stecher G., Peterson D., Filipski A., and Kumar S., 2013. MEGA6: Molecular Evolutionary Genetics Analysis version 6.0. Mol. Biol. Evol.; 30: 2725-2729

7. Excoffier L., Laval G., Schneider S., 2010. Arlequin version 3.1: An integrated software package for population genetics data analysis, Evol. Bioinform. Online; 1: 45-50

8. Hall T.A. 1999. BioEdit: a user-friendly biological sequence alignment editor and analysis program for Windows 95/98/NT. Nucl. Acids. Symp. Ser. 41: 95-98.

9. Pyatt R., Chadwick R. B., Johnson C. K., Adebamowo C., De la Chapelle A., Prior T.W., 1999. Po lymorphic Variation at the BAT-25 and BAT-26 Loci in Individuals of African Origin. Am J Pathol. 155(2): 349-353

10. Mbaye F. 2015. Le cancer du sein chez les femmes sénégalaises : impact des mutations nucleotidiques et de l'instabilite de loci microsatellites. Thèse de doctorat, Université cheikh Anta Diop (Dakar) $\mathbf{N}^{\circ} 154$

11. Zheng Y. Y., Xie L., Liu L., Zhang S. P., Wu X. B., Zhu C. L., Lai R. S., 2012. BAT-25 polymorphism in Chinese from Jiangsu province and its implication for locus microsatellite instability screening. Int J Biol Markers. 27 (3) : e227-31

12. Zhou X.P., Hoang J.M., Cottu P., Thomas G. \& Hamelin R. 1997. Allelic profiles of mononucleotide repeat microsatellites in control individuals and colorectal tumors with and without replication errors. Oncogene. 20 (15): 1713-1718.

13. Billaud M., 2012. Hétérogénéité intra tumorale, un obstacle darwinien à la médecine personnalisée ? Medicine sciences, vol $28, \mathrm{~N}^{\circ} 18$

14. Swanton C., 2012. Intratumor Heterogeneity: Evolution through Space and Time. Cancer Res ; 72(19) ; 4875-82 